\title{
THE ROLE OF FETAL MIDDLE CEREBRAL ARTERY PEAK SYSTOLIC VELOCITY AND INTRAUTERINE TRANSFUSION IN MANAGEMENT OF FETAL ANEMIA IN RH- ALLOIMMUNIZED EGYPTIAN WOMEN
}

\author{
Fahmy A., El Haieg DM, Abdel Aziz R., Mansour.R \\ Departments of obstetrics and gynecology, faculty of medicine, Zagazig University.
}

\begin{abstract}
Objective:To assess the predictive performance of the current reference values of peak systolic velocity of middle cerebral artery (MCA-PSV) in the detection of various degrees of fetal anemia in Rh-alloimmunized Egyptian women and to evaluate pregnancy outcome after prenatal treatment with ultrasound guided intrauterine fetal blood transfusion.

Materials and Methods: In a prospective study, 33 Rh-alloimmunized Egyptian women were evaluated by fetal MCA-PSV. MCA-PSV, intrahepatic umbilical venous maximum velocity (IHUV), liver length, and spleen perimeter were measured. Results before first fetal blood sampling or delivery were analyzed. Perinatal outcome was also recorded.

Results:Thresholds of $\geq 1.50$ and $\geq 1.55$ MOM's MCA-PSV were evaluated with all degrees of fetal anemia. For predicting moderate and severe anemia(Hb $\leq 0.65$ MOM's), MCA-PSVof $\geq 1.50$ MOM's has a $90.6 \%$ sensitivity, $55.0 \%$ specificity with positive likelihood ratio of 2.01 and negative likelihood ratio of 0.17 while IHUV maximum velocity sensitivity was $75 \%$, specificity was $54 \%$, +ve likelihood ratio was 1.4 and -ve likelihood ratio was 0.54.Sensitivity was obviously low for spleen perimeter and liver length (54\%-32\% respectively),also their specificity was (32\%-33\% respectively) in predicting moderate and severe anemia. By addition of IHUV velocity to MCA-PSV, has slightly increased test sensitivity to 94.44 , almost same specificity $54.5 \%$ and predictive performance (+velikelihood ratio $=2.08)$ and lowered false negative values. Total loss was 16/33 (48.5\%) of which $25 \%$ (4/16) had miscarriage (fetal loss < 24 week) and 12 cases $(36.3 \%)$ were early neonatal death in the first week of life. Ten fetuses were anemic by MCA-PSV follow up and required intrauterine transfusion. The total number of transfusions done during the study period was 23 times. Of the 10 pregnant women who required IUT, 4 fetuses ( $40 \%$ ) had died; 1 due to complicated IUT (fetal bradycardia) and 3 had miscarriage due to early severe fetal hydrops. Eighteen cases needed exchange transfusion within 7 days of birth.

Conclusion:It can be concluded that MCA-PSV has limited diagnostic accuracy for the prediction of moderate to severe fetal anemia in Rh-alloimmunized women. Although, it appears superior to other ultrasonographic parameters they need to be interpreted cautiously. Further work should be undertaken to develop test combinations and improve its diagnostic accuracy.
\end{abstract}

Keywords: Rh alloimmunization, fetal anemia, Doppler, Ultrasonography.

\section{INTRODUCTION}

Since the widespread use of preventive $\checkmark$ anti-RhD immunoglobulin in pregnancy and childbirth, hemolytic anemia fetal red cell alloimmunization has become rare. However, it still may persist either because of the failures of existing prevention or lack of prevention in the other groups. ${ }^{(1)}$

The aim of prenatal management protocols of red blood cell alloimmunized pregnancies is to identify affected fetuses, correct their anemia by transfusion and deliver them at the optimal time ${ }^{(2)}$.Therefore, the development of predictive testing for fetal anemia is a constant concern to limit interventions in utero and their complications. (3)
Since 2000, Mari and Deter have demonstrated fetal middle cerebral artery peak systolic velocity (PSV-MCA) role in the measurement of fetal anemia ${ }^{(7)}$. Zimmerman and colleagues and Deren et al, ${ }^{(4)(5)}$ reported a sensitivity of MCA-PSV of $88.9 \%$ and $85 \%$, respectively for detecting moderate and severe anemia. Bartha et al ., 2005 ${ }^{(6)}$ also reported a sensitivity of MCA-PSV of $88 \%$,Carbon B et al, 2008, ${ }^{(1)}$ demonstrated an excellent negative predictive value of $97.8 \%$ over the prospective data. Mari et al (7) reported a negative predictive value $100 \%$. On the other hand, Alshimmiri et al, Sikkel et al ${ }^{(8)}{ }^{(9)}$ reported a lower sensitivity and specificity of MCA-PSV of $12.5 \%$ and $54.3 \%$. Moreover, the accuracy of middle 
cerebral artery peak systolic velocity for detecting fetal anemia has been questioned in recent meta-analysis ${ }^{(3)}$.

Although, intrauterine fetal blood transfusion was found to be the only life saving therapy and very effective in the management of preterm $\mathrm{Rh}$ alloimmunized pregnancies, very few centers in Egypt have the facility or have reported the management and prognosis of high risk pregnant patients with $\mathrm{Rh}$ alloimmunization using ultrasound guided intrauterine fetal blood transfusions. Until recently, management of severe Rhalloimmunization in Zagazig University hospitals, included intensive fetal monitoring for early diagnosis of fetal anemia and preterm delivery and neonatal exchange transfusion as soon as the fetus is about $32-$ 34 weeks of gestation. Plasmapheresis is also offered for selected cases with severe anemia remote from term with limited success.

Therefore, the aim of the present study was to assess the predictive performance of the current reference values of MCA-PSV in detecting various degrees of fetal anemia and to evaluate pregnancy outcome after prenatal treatment with ultrasound guided intrauterine fetal blood transfusion in Rh-alloimmunized Egyptian women.

\section{PATIENT AND METHODS}

During the period from 2011 through 2014, Rh negative allo-immunized pregnant women attending either at fetal medicine unit, kasr El Aini maternity hospital, Cairo University, or at obstetrics and gynecology department, Zagazig University hospitals, Zagazig University Egypt, participated in the study.

\section{Inclusion criteria:}

- Rh negative alloimmunized singleton pregnancies with indirect coomb's test titre $\geq 1 / 16$.

- Reliable gestational age confirmed by the latest reliable menstruation date and by late $1^{\text {st }}$ trimester or early $2^{\text {nd }}$ trimester ultrasound.

Exclusion criteria:

- Multiple pregnancy

- Non-immune hydropsfetalis.
- Isolated fetal ascites, effusion or subcutaneous oedema.

- Major fetal congenital anomalies.

- Contraindications to cordocentesis:

1. Vaginal bleeding.

2. Bleeding tendency.

3. Rupture of membrane and oligohydramnios.

Serial ultrasound examinations were performed to assess fetal problems starting from 18 weeks gestation eg. hepatomegaly, spleenomegaly, placentomegaly, cardiomegaly, polyhydramnios, hydrops. Intrahepatic umbilical vein velocity, spleen perimeter and liver length were recorded. If values were greater than the 95th percentile for all these measurements, they are considered abnormal.

Serial middle cerebral artery -peak systolic velocity (MCA-PSV) assessment using Color Doppler was performed at regular intervals (1-3 weeks). The MCA measurements with cut-off value of 1.5 MOM's were considered abnormal.

If the MCA -PSV reaches >1.5 MoMs by Mari's normogram with gestational age more than 34 weeks, delivery was considered ${ }^{(7) .}$

If the MCA -PSV reaches >1.5 MoMs with gestational age of less than 34 weeks, cordocentesis was performed for fetal blood sampling (hemoglobin, hematocrit, and blood group - ABO \&Rh) with blood readied for intra-uterine transfusion for fetal haemoglobin less than 0.65 MOM's. ${ }^{(10)}$

The fetal Middle Cerebral Artery (MCA) was identified in the following manner: the circle of Willis was located in the fetal head at the level of the cerebral peduncles using color Doppler mode. The MCA was observed passing anteriorly to the peduncles, close to the greater wing of the sphenoid bone, with the angle of insonation being close to zero. The sample volume was placed approximately $1 \mathrm{~cm}$ from the beginning of the vessel from the circle of Willis. ${ }^{(1)}$

The intra hepatic umbilical vein maximum velocity (IHUV): "It was measured in a cross-section of the fetal abdomen. The sample volume was placed at approximately one third of the distance between the abdominal wall and the portal vein, with the 
gate adjusted to the diameter of the vessel. A steady flow velocity pattern of 5 seconds was obtained before freezing the image. The maximum velocity was measured by placing a caliper with the horizontal lines on the edge of the Doppler signal." ${ }^{\prime(2)}$

Maximum fetal liver length: It was measured in a parasagittal scan of the fetal abdomen from the diaphragm to the lower edge of the right lobe of the liver.The fetal spleen perimeter: It was measured by the trace method in the same cross-sectional plane as used for the fetal stomach. ${ }^{(2)}$

Placental thickness is measured at its midportion, from the chorionic plate to the basilar plate, on a longitudinal plane. By and large, the placental thickness in millimeters corresponds to the weeks of gestation. Rarely, placental thickness can exceed $4 \mathrm{~cm}$ at term. ${ }^{(15)}$

The cardiothoracic circumference ratio should be always less then 0.5 throughout gestation. It slowly increased through gestation. At 11 weeks: 0.38, 17-20 weeks: 0.45 and term: 0.5 . Increased $\mathrm{C} / \mathrm{T}$ circumferential ratios can be be observed with either cardiac or thoracic pathology (16)

\section{RESULTS}

During the study period, a total of 33 $\mathrm{Rh}$ negative alloimmunized pregnant women, who met the inclusion criteria, have benefited from the entire monitoring protocol provided. Their mean age was $31.4 \pm 4.9$ years (from 23 to 42 years), gravidity ranging from 2-8 (mean $=4.2 \pm 2.0$ ) and parity ranging from $0-6$ (mean $=2.5 \pm 1.7)$. Number of living children ranged from 0-3 living children (mean= $1.8 \pm 1.2) ; 72.7 \%(24 / 33)$ had $\leq 1$ child and $27.3 \%$ patients $(9 / 33)$ had more than one living children.

Development of hydrops fetalis in a previous pregnancy was observed in 21 patients $(63.6 \%)$, while 4 patients $(12 \%)$ had history of IUT in a previous pregnancy. Twenty six patients have never taken anti-D anti-Rh immunoglobin $(26 / 33 ; 78.8 \%)$ in their previous pregnancies.

A total of 308 measures of PSV-MCA were done. They ranged from $31-113 \mathrm{~cm} / \mathrm{s}$. An average of 9.5 \pm 3.2 measures were performed for each patient (from 3 to 16) during follow-up and the average interval between two measurements of MCA-PSV was 2 week (range $=1-3 \mathrm{w}$, mean $\pm \mathrm{SD}=1.47 \pm 0.6$ ).

Of the 308 PSV values, 52 were obtained immediately before cordocentesis (23 times) for measurement of hemoglobin concentrations or within 7days before delivery (29 times). These are the values that were included for statistical analysis. 13 cases reached or exceeded 34 weeks and delivered all good neonatal outcome.(Table 1)

There is a highly significant negative spearman rank correlation between fetal heamoglobin MOM's and MCA-PSV MOM's $(\mathrm{r}=-0.61 ; \mathrm{P}=<0.001)$.

Table:1 MCA PSV values

Fetal Hb MOM's (N = 52)

\begin{tabular}{|c|c|c|c|c|c|}
\hline \multirow{2}{*}{$\begin{array}{l}\text { MCA-PSV } \\
\text { MOM's }\end{array}$} & \multirow{2}{*}{$\begin{array}{c}\mathrm{Hb}>0.84 \\
n=6\end{array}$} & \multicolumn{4}{|c|}{$H b \leq 0.84 \quad n=46$} \\
\hline & & $\begin{array}{l}\text { Total } \\
n=46\end{array}$ & $\begin{array}{c}\mathrm{Hb} \leq 0.84->0.65 \\
n=14\end{array}$ & $\begin{array}{c}\leq 0.65->0.55 \\
n=12\end{array}$ & $\begin{aligned} \mathrm{Hb} & \leq \mathbf{0 . 5 5} \\
\mathrm{n} & =20\end{aligned}$ \\
\hline$<1.5(n=14)$ & 3 & 11 & 8 & 2 & 1 \\
\hline$\geq 1.5-<1.55(\mathrm{n}=9)$ & 1 & 8 & 1 & 4 & 3 \\
\hline$\geq 1.55(n=29)$ & 2 & 27 & 5 & 6 & 16 \\
\hline
\end{tabular}


When MCA-PSV test threshold of 1.5 MoM and any degree of fetal anaemia with haemoglobin cutoff $\leq 0.84$ MOM's was used, sensitivity was $76.09 \%$ (95\% CI: $61.23 \%$ to $87.40 \%)$, specificity was $50.0 \%(95 \%$ CI: $12.42 \%$ to $87.58 \%$ ), Positive Predictive value was $92.11 \%(95 \%$ CI: $78.60 \%$ to 98.25 $\%)$, Negative Predictive value was $21.43 \%$ (95\% CI: $4.91 \%$ to $50.79 \%$ ), +ve likelihood ratio was 1.52 (95\% CI: 0.67 to 3.44 ) and -ve likelihood ratio was $0.48(95 \%$ CI: 0.18 to 1.24). (Table 2)

When MCA-PSV test threshold of 1.5 MoM and moderate and severe fetal anaemia with haemoglobin cutoff $\leq 0.65$ MOM's was used, sensitivity was $90.6 \%$ (95\% CI:74.95\% to $97.91 \%$ ), specificity was $55.0 \%(95 \%$ CI:31.55 \% to $76.90 \%$ ), Positive Predictive value was 76.3\%(95\% CI:59.75\% to 88.53), Negative Predictive value was $78.6 \%$ (95\% CI:49.21 \% to 95.09), +ve likelihood ratio was 2.01 (95\% CI: 1.22 to $3.31)$ and -ve likelihood ratio was $0.17(95 \%$ CI: 0.05 to 0.54 ). (Table 2)

When MCA-PSV test threshold of 1.5 MoM and severe fetal anaemia with haemoglobin cutoff $\leq 0.55$ MOM's was used, sensitivity was $95.0 \%$ (95\% CI: $75.05 \%$ to $99.17 \%)$, specificity was $40.6 \%(95 \%$ CI: $23.71 \%$ to $59.35 \%$ ), Positive Predictive value was $50.0 \%(95 \%$ CI: $33.39 \%$ to 66.61 $\%)$, Negative Predictive value was $92.9 \%$ (95\% CI: $66.06 \%$ to $98.81 \%$ ), +ve likelihood ratio was 1.6 (95\% CI: 1.18 to 2.17) and -ve likelihood ratio was $0.12(95 \% \mathrm{CI}$ : 0.02 to 0.87).(Table 2)
When MCA-PSV test threshold of $1.55 \mathrm{MoM}$ and any degree of fetal anaemia with haemoglobin cutoff $\leq 0.84$ MOM's was used, sensitivity was $87.1 \%$ (95\% CI: 70.15 $\%$ to $96.29 \%)$, specificity was $9.52 \%(95 \%$ CI: $1.45 \%$ to $30.42 \%$ ), Positive Predictive value was $58.70 \%$ (95\% CI: $43.23 \%$ to 73.00 $\%$ ), Negative Predictive value was $33.33 \%$ (95\% CI:5.33\% to $77.32 \%$ ), +ve likelihood ratio was 0.96 (95\% CI: 0.79 to 1.17$)$ and -ve likelihood ratio was $1.35(95 \%$ CI: 0.27 to 6.74). (Table 2)

When MCA-PSV test threshold of 1.55 MoM and moderate and severe fetal anaemia with haemoglobin cutoff $\leq 0.65$ MOM's was used, sensitivity was $68.8 \%$ (95\% CI: 49.99 $\%$ to $83.86 \%)$, specificity was $65.0 \%(95 \%$ CI: $40.79 \%$ to $84.55 \%$ ), Positive Predictive value was $75.9 \%(95 \%$ CI: $56.45 \%$ to 89.66 $\%)$, Negative Predictive value was $56.5 \%$ (95\% CI: $34.51 \%$ to $76.78 \%$ ), +ve likelihood ratio was 1.96 (95\% CI: 1.03 to 3.73 ) and -ve likelihood ratio was $0.48(95 \%$ CI: 0.26 to 0.88). (Table 2)

When MCA-PSV test threshold of 1.55 MoM and severe fetal anaemia with haemoglobin cutoff $\leq 0.55$ MOM's was used, sensitivity was $80.0 \%$ (95\% CI: $56.33 \%$ to $94.14 \%)$, specificity was $59.4 \%(95 \%$ CI: $40.65 \%$ to $76.29 \%$ ), Positive Predictive value was $55.2 \%(95 \%$ CI: $35.70 \%$ to 73.54 $\%)$, Negative Predictive value was $82.6 \%$ (95\% CI: $61.20 \%$ to $94.94 \%$ ), +ve likelihood ratio was 1.97 (95\% CI: 1.23 to 3.16) and-ve likelihood ratio was $0.34(95 \%$ CI: 0.13 to 0.85).(Table 2) 
Table (2): Predictive performance of fetal middle cerebral artery- peak systolic velocity of a threshold $(\geq 1.50$ and $\geq 1.55$ MOM's) in predicting fetal anemia for fetal hemoglobin concentrations $\leq 0.84 M O M \prime s, \leq 0.65 \mathrm{MOM}$ 's and $\leq 0.55 \mathrm{MOM}$ 's below the normal median for gestation.

\begin{tabular}{|c|c|c|c|c|c|c|c|}
\hline $\begin{array}{c}\text { MCA-PSV cut- } \\
\text { off } \\
\text { MOM's }\end{array}$ & $N$ & $\begin{array}{l}\text { Sensitivity } \\
(95 \% C I)\end{array}$ & $\begin{array}{l}\text { Specificity } \\
(95 \% \text { CI })\end{array}$ & $\begin{array}{c}P P V \\
(95 \% C I)\end{array}$ & $\begin{array}{c}N P V \\
(95 \% C I)\end{array}$ & $\begin{array}{c}\text { Positive } \\
\text { Likelihood } \\
\text { Ratio } \\
(95 \% \text { CI })\end{array}$ & $\begin{array}{c}\text { Negative } \\
\text { Likelihood } \\
\text { Ratio } \\
(95 \% \text { CI })\end{array}$ \\
\hline $\begin{array}{c}\text { MCA-PSV } \\
\text { MOM's } \geq 1.50\end{array}$ & 38 & & & & & & \\
\hline $\begin{array}{l}\text { Hemoglobin } \\
\text { MOM's } \leq 0.84 \\
\text { (any degree of } \\
\text { anemia) }\end{array}$ & 35 & $\begin{array}{l}76.09 \\
(\mathbf{6 1 . 2 3} \% \text { to } \\
\mathbf{8 7 . 4 0 \% )}\end{array}$ & $\begin{array}{c}50.0 \\
(\mathbf{1 2 . 4 2 \%} \% \text { to } \\
\mathbf{8 7 . 5 8 \% )}\end{array}$ & $\begin{array}{c}92.11 \\
\text { (78.60\% } \\
\text { to } 98.25 \\
\%)\end{array}$ & $\begin{array}{c}21.43 \\
(\mathbf{4 . 9 1 \%} \text { to } \\
\mathbf{5 0 . 7 9 \% )}\end{array}$ & $\begin{array}{c}1.52 \\
(\mathbf{0 . 6 7} \% \text { to } 3.44 \%)\end{array}$ & $\begin{array}{c}0.48 \\
(\mathbf{0 . 1 8 \%} \text { to } \\
\mathbf{1 . 2 4 \%})\end{array}$ \\
\hline $\begin{array}{l}\text { Hemoglobin } \\
\text { MOM's } \leq 0.65 \\
\text { (moderate \& }\end{array}$ & 29 & $\begin{array}{c}90.6 \% \\
(\mathbf{7 4 . 9 5 \%} \text { to } \\
\mathbf{9 7 . 9 1 \% )}\end{array}$ & $\begin{array}{c}55.0 \% \\
(\mathbf{3 1 . 5 5 \%} \text { to } \\
\mathbf{7 6 . 9 0 \% )}\end{array}$ & $\begin{array}{c}76.3 \% \\
\mathbf{5 9 . 7 5 \%} \\
\text { to } \mathbf{8 8 . 5 3 \%}\end{array}$ & $\begin{array}{c}78.6 \% \\
(\mathbf{4 9 . 2 1 \%} \text { to } \\
\mathbf{9 5 . 0 9 )}\end{array}$ & $\begin{array}{c}2.01 \\
(\mathbf{1 . 2 2} \% \text { to } \mathbf{3 . 3 1} \%)\end{array}$ & $\begin{array}{c}0.17 \\
(\mathbf{0 . 0 5} \% \text { to } \mathbf{0 . 5 4} \%)\end{array}$ \\
\hline $\begin{array}{c}\text { Hemoglobin } \\
\text { MOM's } \leq 0.55 \\
\text { (severe anemia) }\end{array}$ & 19 & $\begin{array}{c}95.0 \% \\
(\mathbf{7 5 . 0 5 \%} \text { to } \\
\mathbf{9 9 . 1 7 \% )}\end{array}$ & $\begin{array}{c}40.6 \% \\
(\mathbf{2 3 . 7 1 \%} \text { to } \\
\mathbf{5 9 . 3 5 \% )}\end{array}$ & $\begin{array}{c}50.0 \% \\
(\mathbf{3 3 . 3 9} \% \\
\text { to } \mathbf{6 6 . 6 1} \\
\mathbf{\%})\end{array}$ & $\begin{array}{c}92.9 \% \\
(\mathbf{6 6 . 0 6 \%} \text { to } \\
\mathbf{9 8 . 8 1 \%})\end{array}$ & $\begin{array}{c}1.6 \\
(\mathbf{1 . 1 8} \% \text { to } \mathbf{2 . 1 7} \%)\end{array}$ & $\begin{array}{c}0.12 \\
(\mathbf{0 . 0 2} \% \text { to } \mathbf{0 . 8 7 \%})\end{array}$ \\
\hline $\begin{array}{c}\text { MCA-PSV } \\
\text { MOM's } \geq 1.55\end{array}$ & 29 & & & & & & \\
\hline $\begin{array}{c}\text { Hemoglobin } \\
\text { MOM's } \leq 0.84 \\
\text { (any degree of } \\
\text { anemia) }\end{array}$ & 27 & $\begin{array}{c}87.10 \% \\
(\mathbf{7 0 . 1 5} \\
\text { \% to } 96.29 \\
\%)\end{array}$ & $\begin{array}{c}9.52 \% \\
(\mathbf{1 . 4 5} \\
\% \text { to } 30.42 \\
\%)\end{array}$ & $\begin{array}{c}58.70 \\
\%(43.23 \\
\% \text { to } 73.00 \\
\%)\end{array}$ & $\begin{array}{c}33.33 \% \\
(5.33 \\
\% \text { to } 77.32 \\
\%)\end{array}$ & $\begin{array}{c}0.96 \\
(\mathbf{0 . 7 9 \%} \text { to } 1.17 \%)\end{array}$ & $\begin{array}{c}1.35 \\
(0.27 \% \text { to } 6.74 \%)\end{array}$ \\
\hline $\begin{array}{c}\text { Hemoglobin } \\
\text { MOM's } \leq 0.65 \\
\text { (moderate \& } \\
\text { severe anemia) }\end{array}$ & 22 & $\begin{array}{c}68.8 \% \\
(\mathbf{4 9 . 9 9 \%} \text { to } \\
\mathbf{8 3 . 8 6 \% )}\end{array}$ & $\begin{array}{c}65.0 \% \\
(\mathbf{4 0 . 7 9 \%} \text { to } \\
\mathbf{8 4 . 5 5 \% )}\end{array}$ & $\begin{array}{c}75.9 \% \\
(\mathbf{5 6 . 4 5} \% \\
\text { to } \mathbf{8 9 . 6 6} \\
\mathbf{\%})\end{array}$ & $\begin{array}{c}56.5 \% \\
(\mathbf{3 4 . 5 1 \%} \text { to } \\
\mathbf{7 6 . 7 8 \%})\end{array}$ & $\begin{array}{c}1.96 \\
(\mathbf{1 . 0 3} \% \text { to } \mathbf{3 . 7 3} \%)\end{array}$ & $\begin{array}{c}0.48 \\
(\mathbf{0 . 2 6} \% \text { to } \mathbf{0 . 8 8} \%)\end{array}$ \\
\hline $\begin{array}{c}\text { Hemoglobin } \\
\text { MOM's } \leq 0.55 \\
\text { (severe anemia) }\end{array}$ & 16 & $\begin{array}{l}80.0 \% \\
(\mathbf{5 6 . 3 3} \% \text { to } \\
\mathbf{9 4 . 1 4} \%)\end{array}$ & $\begin{array}{c}59.4 \% \\
(\mathbf{4 0 . 6 5 \%} \text { to } \\
\mathbf{7 6 . 2 9 \% )}\end{array}$ & $\begin{array}{c}55.2 \% \\
\mathbf{( 3 5 . 7 0 \%} \\
\text { to } \mathbf{7 3 . 5 4} \\
\mathbf{\%})\end{array}$ & $\begin{array}{l}82.6 \% \\
(\mathbf{6 1 . 2 0} \% \text { to } \\
\mathbf{9 4 . 9 4 \% )}\end{array}$ & $\begin{array}{c}1.97 \\
(\mathbf{1 . 2 3} \% \text { to } \mathbf{3 . 1 6 \% )}\end{array}$ & $\begin{array}{c}0.34 \\
(\mathbf{0 . 1 3} \% \text { to } \\
\mathbf{0 . 8 5 \%})\end{array}$ \\
\hline
\end{tabular}


Intra hepatic umbilical venous maximum velocity values more than the $95^{\text {th }}$ centile were used as abnormal results. Thirty three values were abnormal, of which 18 were moderate \& severe anemia $(\leq 0.65$ MOM's) and 15 were normal hemoglobin level. When IHUV was abnormal and moderate and severe fetal anaemiawith cutoffhaemoglobin $\leq 0.65$ MOM's was used, sensitivity was $75 \%$, specificity was $46 \%, 1.4$ as+ve likelihood ratio and 0.54 as -ve likelihood ratio. (Table 3)

Greater than the $95^{\text {th }}$ percentile spleen perimeter values were considered abnormal. Thirty two values were abnormal, of which 13 were moderate \& severe anemia $(\leq 0.65$ MOM's) and 19 were normal hemoglobin level. When Spleen perimeter was abnormal and moderate and severe fetal anaemiawith cutoffhaemoglobin $\leq 0.65$ MOM's was used, sensitivity was $54 \%$, specificity was $32 \%$, +ve likelihood ratio was 0.79 and -ve likelihood ratio was 1.44. (Table 3 )

Greater than the $95^{\text {th }}$ percentile liver length values were considered abnormal. Thirty three values were abnormal, of which 13 were moderate \& severe anemia $(\leq 0.65$ MOM's) and 20 were normal hemoglobin level. When liver length was abnormal and moderate and severe fetal anaemiawith cutoff haemoglobin $\leq 0.65$ MOM's was used, sensitivity was $59 \%$, specificity was $33 \%$, +ve likelihood ratio was 0.88 and -ve likelihood ratio was 1.24. (Table 3)

Table: 3.Predictive performance of $\geq 1.5 \mathrm{MCA}-\mathrm{PSV}, \quad$ IHUV velocity, spleen perimeter and liver length $\geq 95^{\text {th }}$ centile in the prediction of fetal anemia for fetal hemoglobin concentrations $\leq 0.65 \mathrm{MOM} \mathrm{M}^{\prime}$.

\begin{tabular}{cccccc}
\hline & $\begin{array}{c}\text { \1.5 MCA- } \\
\text { PCV }\end{array}$ & IHUV & SPLEEN & LIVER & $\begin{array}{c}\text { Compination of } \\
\text { MCA-PSV and } \\
\text { IHUV }\end{array}$ \\
\hline Sensitivity & $90.6 \%$ & $75 \%$ & $54 \%$ & $59 \%$ & $94.44 \%$ \\
Specificity & $55 \%$ & $46 \%$ & $32 \%$ & $33 \%$ & $54.55 \%$ \\
+veliklyhood ratio & 2.01 & 1.4 & 0.79 & 0.88 & 2.08 \\
-veliklyhood ratio & 0.17 & 0.54 & 1.44 & 1.24 & 0.10 \\
\hline
\end{tabular}

The overall live birth rate was $51.5 \%$ (17/33). The mean of their gestational age at birth was $35.5 \pm 5.3$ weeks (range 32 to 41 ). Median of birth weight was 2206 gm with IQR 1600-3000 gm. Four fetuses (4 /33; $12.2 \%)$ were Rh- negative blood group.

Total loss was $16 / 33(48.5 \%)$ of which $25 \%$ (4/16) had miscarriage (fetal loss $<24$ weeks $^{(11)}$ and 12 cases $(36.3 \%)$ were early neonatal death in the first week of life.

Of the 10 pregnant women who required IUT, 4 fetuses (40\%) had died; 1 due to complicated IUT (fetal bradycardia) and 3 had miscarriage due to early severe fetal hydrops.

Of the other 23 women who didn't require IUT, 12 fetuses were lost; 6 due to severe hydrops, 3 had severe anemia and died following exchange transfusion and 3 miscarried.

\section{DISCUSSION}

The aim of our study was to assess the predictive performance of the current reference values of MCA-PSV in detecting various degrees of fetal anemia in $\mathrm{Rh}$ alloimmunized Egyptian women. During the study period, a total of $33 \mathrm{Rh}$ negative alloimmunized pregnant women have been evaluated. Of the 308 MCA-PSV values measured, 52 were obtained immediately before cordocentesis for measurement of hemoglobin concentrations or within 7days before delivery. There was a highly significant negative correlation between fetal heamoglobin and MCA-PSV MOM's ( $\mathrm{r}=$ $0.61 ; \quad \mathrm{P}=<0.001)$. However, this good 
correlation does not allow concluding the performance of this test for predicting fetal anemia.

The predictive performance of the MCA-PSV for detecting various degrees of fetal anemia looks good. The best sensitivity obtained was $95 \%$ upon using threshold of $\geq 1.50$ MOM's in the prediction of severe anemia $(\mathrm{Hb} \leq 0.55$ MOM's) with specificity of $40.6 \%$, positive likelihood ratio $(\mathrm{LR}+)$ of 1.6 and negative likelihood ratio (LR-) of 0.12 . While on using the same threshold of $\geq 1.50$ MOM's in detection of moderate and severe anemia $(\mathrm{Hb}$ $\leq 0.65 \mathrm{MOM}$ 's) the sensitivity was $90.6 \%$, specificity $55.0 \%, \mathrm{LR}+$ of 2.01 , LR- of 0.17 . Using the threshold of $\geq 1.55$ decreased the false positive rate (specificity 65\%) for predicting moderate and severe anemia $(\mathrm{Hb}$ $\leq 0.65$ MOM's) on the expense of the sensitivity which decreased to $68.8 \%$.

MCA-PSV was considered as a sensitive noninvasive screening tool, however; in the present studythe positive likelihood ratio was weakly useful $(<5)$, and the negative likelihood ratio was moderately useful (0.10.2 ) in detecting moderateand severe anemia. Given that false positive results may lead to unnecessary invasive procedures, it is essential that the positive likelihood ratio of the test to be properly high. On the other hand, the false negative results may increase the fetal morbidity if left untreated, therefore; it is essential that the negative likelihood ratio of the test to be properly low.

In their systematic review, pertezlove et al .2009 provided ahigh evidence that the diagnostic accuracy of MCA-PSV is not that of an ideal test ${ }^{(3)}$. The positive and negative likelihood ratios were weakly accurate; the LR+ was 4.30 (95\% CI: 2.50 to 7.41$)$ and LRwas 0.30 (95\% CI: 0.17 to 0.59$)$ in detecting severe anaemia.

In order to improve the diagnostic accuracy,we evaluated other ultrasound parameters; intrahepatic umbilical venous maximum velocity, liver length, and spleen perimeter. MCA-PSV, however; was a superior test in the detection of fetal anemia. IHUV maximum flow velocity achieved $75 \%$ sensitivity, $46 \%$ specificity, LR+ was 1.4 and LR- was 0.54. Spleen perimeter and liver length showed poorer predictive performance with sensitivities and specificity of $54 \%$ and $59 \%$ and $32 \%$ and $33 \%$ respectively. When a test threshold for MCA-PSV of 1.5 MOM and IHUV maximum velocity values were combined withmoderate and severe fetal anaemia of haemoglobin cutoff $\leq 0.65$ MOM's, sensitivity was $94.44 \%$, specificity was $54.55 \%$, positive likelihood ratio was 2.08 and negative likelihood ratio was 0.10 . It's obvious that adding IHUV velocity to MCAPSV had no significant added value.

Dukler et al Madazil et al and Iskaros et $\boldsymbol{a l}^{(\mathbf{1 2 ) ( 2 ) ( 1 3 )}}$ have also demonstrated that MCA-PSVwas more accurate in predictinganemia than umbilical vein maximal flow velocity,liver length and spleen perimeter measurement. These results may indicate that the fetus may have hepatosplenomegaly but would not inevitably be severely anemic due to the compensatory increased red blood cells production. In opposition, rapid breakdown of RBC's may prevent the fetus from adaptation mechanism, and anemia may develop without enlarged liver or spleen.

As MCA-PSV in our study is of weak to moderate diagnostic accuracy even after adding more ultrasound parameters, additionalstudies should be undertaken to develop more test combinations and to improve its diagnostic accuracy.

. It is also recommended that when MCAPSV value reach a threshold level it should be confirmed on another 2 or more occasions before proceeding to cordocentesis in order to reduce the false positive results.

Cabral et al 2010., ${ }^{(14)}$ stated that combination of the middle cerebral artery Doppler velocimetry and cardiofemoral index for predicting fetal anemia yielded a sensitivity of $100 \%$ but it still need more evaluation by larger number of cases ${ }^{(15)}$.

Pregnancy outcomes followed in our study confirm that alloimmunization is a serious situation with high fetal and neonatal risk. Of the 33 pregnancies, 10 (about $30 \%$ ) have required one or more cordocentesis followed by in utero transfusion (one to six per pregnancy; 6 cases once, 1 case twice, 1 case 4 times and two cases 5 times). Interval 
between this intervention was ranging from 13 weeks according to MCA-PSV values. The total number of transfusions done during the study period was 23 times. Eighteen cases needed exchange transfusion within 7 days of birth.

The overall live birth rate was $17 / 33$ (51.5\%). Of the 10 pregnant women who required IUT, 4 fetuses had died; 1 due to complicated IUT (fetal bradycardia) and 3 had miscarriage due to early severe fetal hydrops. So success rate was $60 \%$, this may be due to presence of severe early fetal hydrops in 3 cases and may be in part due to the relatively recent experience in intrauterine blood transfusion technique where by increasing learning curves, better results will be obtained.

Conclusion: It can be concluded that middle cerebral artery- peak systolic velocity has limited diagnostic accuracy for the prediction of moderate to severe fetal anemiain $\mathrm{Rh}$ alloimmunized women.Although, it appears superior to other ultrasonographicparameters they need to be interpreted cautiously. Further studiesshould be undertaken to develop more test combinations and to improve its diagnostic accuracy.

\section{REFERENCES}

1- Carbonne B, Castiagne-Meary V, Cynober E, Gougeul-Tesniere V, Cortey A, Soulie J-C,et al.: Practical value of the peak systolic velocity in middle cerebral artery in the management of fetal anemia with red cell alloimmunization .Peak systolic velocity of Use in the middle cerebral artery in the management of fetal anemia due to fetomaternal alloimmunization. Journal of Obstetrics and Gynecology Reproductive Biology Vol 37, April (2)2008 ; 163-169.

2-Madazli R: Noninvasive Doppler and ultrasound parameters to predict fetal anemia due to red blood cell alloimmunization. Marmara Medical Journal 2007; 20(3);172-178

3-Peretzlove S, Fox C, Khan K, Kilby M.: Noninvasive methods of detecting fetal anaemia: a systematic review and metaanalysis. BJOG. 2009;116:1558-1567.

4-Zimmerman R, Carpenter R J, Jr, Durig P, Mari $\mathrm{G}$, : "Longitudinal measurement of peak systolic velocity in the fetal middle cerebral artery for monitoring pregnancies complicated by red cell alloimmunisation: a prospective multicentre trial with intentionto-treat", Br. J. Obstet. Gynaecol. (2002), 109: pp. 746-752.

5-Deren O, Onderoglu L.: The value of middle cerebral artery systolic velocity for initial and subsequent management in fetal anemia. Eur $\mathbf{J}$ Obstet Gynecol Reprod Biol 2002;101:26-30.

6-Bartha J. L., Illanes S., Abdel-Fattah S., Hunter A., Denbow M. and Soothill P. W.: Comparison of different reference values of fetal blood flow velocity in the middle cerebral artery for predicting fetal anemia .Ultrasound Obstet Gynecol 2005; 25: 335-340

7-Mari G, Deter RL, Carpenter RL, Rahman F, Zimmerman R, Moise KJ Jr, et al.: Noninvasive diagnosis by Doppler ultrasonography of fetal anemia due to maternal red-cell alloimmunization. Collaborative Group for Doppler Assessment of the Blood Velocity in Anemic Fetuses.N Engl J Med 2000;342:9-14.

8-Alshimmiri MM, Hamoud MS, Al Saleh EA, Mujaibel KY, Al Harmi JA, Thalib L.: Prediction of fetal anemia by middle cerebral artery peak systolic velocity in pregnancies complicated by rhesus isoimmunization. J. Perinatol. (2003);23:536-40.

9-Sikkel E, Vandenbussche FP, Oepkes D, Klumper FJ, Teunissen KA, Meerman RH,et al.: Effect of an increase of the hematocrit on middle cerebral artery peak and umbilical vein maximum velocities in anemic fetuses. Fetal Diagn Ther2003; 18:472-8.

10-Arora LC , Bhattacharyya CT, Kathpalia CS, Kochar CS, Sandhu GC, Goyal CB: Management of Rh-isoimmunised Pregnancies : Our Experience MJAFI. 2007; Vol. 63(1): 7110.

11-RCOG: The Investigation and Treatment of Couples with Recurrent First-trimester and Second-trimester Miscarriage. Green-top Guideline No. 17.April 2011; 1-18.

12-Dukler D, Oepkes D, Seaward G, Windrim R, Ryan G.: Noninvasive tests to predict fetal anemia: A study comparing Doppler and ultrasound parameters. Am J Obstet Gynecol 2003; 188:1310-1314.

13-Iskaros J, Kingdom J, Morrison JJ, Rodeck $\mathrm{CH}$.: Prospective non-invasive monitoring of pregnancies complicated by red cell alloimmunization. Ultrasound Obstet Gynecol 1998; 11:432-437

14-Cabral AC, Reis Z, Apocalypse IG, Osanan GC, Lage EM, Leite HV: Combined use of the cardiofemoral index and middle cerebral artery Doppler velocimetry for the prediction of fetal 
anemia. International Journal of Gynecology and Obstetrics.111 (2010) 205-8.

15-Kinare A.: Fetal environment. Indian J Radiol Imaging. 2008 Nov; 18(4): 326-344.
16-Paladini D, Chita S K, and Allan L D: Prenatal measurement of cardiothoracic ratio in evaluation of heart disease. Arch Dis Child. 1990 Jan; 65(1 Spec No): 20-23 